\title{
Experimental Study on Failure Mechanism of Flexural Reinforced Concrete Beams in Fatigue Load
}

\author{
Haiqian Wang ${ }^{1, a}$, Hongyu Zhou*1, b , Yibo Chen ${ }^{1, c}$ and Junchang $\mathrm{Ci}^{1, \mathrm{~d}}$ \\ ${ }^{1}$ Beijing University of Technology, Beijing 100124, P.R. China \\ awanghaiqian121@163.com, bzhouhy@bjut.edu.cn, \\ ccyb19891105@163.com, ${ }^{\mathrm{d}}$ cijunchang@126.com
}

\begin{abstract}
Keywords: Reinforced concrete simple beams. Fatigue load. Fatigue failure mechanism.
Abstract. Fatigue load applied to a group of test beams at identical stress level and identical frequency but different cycles. Research on fatigue performance of the group specimens such as steel strain and deflection curve along with the change of fatigue load cycles. Reveal the fatigue failure mechanism of flexural reinforced concrete beams in fatigue load.
\end{abstract}

\section{Introduction}

Reinforced concrete member has been widely used in bridge engineering, port engineering, ocean engineering, and other structures under fatigue load for a long time such as vehicles, water, nuclear power, etc. At present, the study of the fatigue property of reinforced concrete beam mainly focused on the fatigue life, fatigue property and fatigue damage, etc.

Moss $^{[1][2]}$ found the discreteness of reinforced fatigue life is higher,and under the same fatigue life, stress amplitude of steel destruction caused by axial tensile fatigue generally lower than the bending fatigue. Zhang $\mathrm{B}^{[3]}$ studied the stress value and the influence of loading frequency on concrete fatigue life through experiment, though that the residual strain accumulated gradually and deformation modulus degenerated constantly in the process of fatigue damage,and established fatigue damage model of concrete under uniaxial compressive.Shibin $\mathrm{Li}^{[4]}$ obtained a method to prediction the fatigue life of concrete beam through the limited time of fatigue load. Zhong Ming ${ }^{[5]}$ regressed and deduced the calculation formula of crack width. Ruimin Wang ${ }^{[6]}$ had studied and deduced the calculation formula of component stiffness degradation and crack width. Huimin $\mathrm{Li}^{[7]}$ analyzed the stress distribution of stirrup and the stress process through shear fatigue test, put forward the fatigue coefficient of oblique section strength and the control values of diagonal crack width.

Based on the experimental study on six test beams, including 4 pieces for fatigue test, 2 pieces for static load test, analyze failure characteristics of reinforced concrete beam under fatigue load and reveal fatigue failure mechanism.

\section{Test Survey}

Test beams section size is $100 \mathrm{~mm} \times 250 \mathrm{~mm}$, length is $1725 \mathrm{~mm}$ and concrete strength is C30. The under edge of test beams configure HRB400 steel whose diameter is $12 \mathrm{~mm}$, the upper edge configure HRB400 steel whose diameter is 10mm. Stirrups use HRB300 steel whose diameter is $8 \mathrm{~mm}$ and spacing is $80 \mathrm{~mm}$. A total of 6 test beams, including 2 pieces for static load test which are JD1、JD2, 4 pieces for fatigue test which are JP2、JP3、JP4、JP5. Grouping of reinforced concrete beam by loading method is shown in table 1 , the test conditions and basic results reference literature [8]. 
Table1 Grouping of reinforced concrete beam by loading method

\begin{tabular}{cccccc}
\hline number & loading method & highest load & lowest load & fatigue load cycles & frequency \\
\hline JD1 & static load & - & - & - & - \\
JD2 & static load & - & - & - & - \\
JP2 & fatigue loading & $0.6 \mathrm{Pu}$ & $0.12 \mathrm{Pu}$ & 153000 times & $5 \mathrm{HZ}$ \\
JP3 & fatigue loading & $0.6 \mathrm{Pu}$ & $0.12 \mathrm{Pu}$ & 213000 times & $5 \mathrm{HZ}$ \\
JP4 & fatigue loading & $0.6 \mathrm{Pu}$ & $0.12 \mathrm{Pu}$ & 100000 times & $5 \mathrm{HZ}$ \\
JP5 & fatigue loading & $0.6 \mathrm{Pu}$ & $0.12 \mathrm{Pu}$ & 150000 times & $5 \mathrm{HZ}$ \\
\hline
\end{tabular}

\section{JD1 and JD2 Failure Mechanism}

Failure pattern of JD1 and JD2 is shown in figure 1 and 2. When the reinforced concrete beam were destroyed, the concrete compressive cracked, tensile longitudinal reinforcement yield without fracture, which belong to reinforcement beam damage.

After the experimental beam yield, with increasing deformation of reinforced concrete beam, tensile longitudinal reinforcement strain increased, stress did not change obviously; neutral axis was rising; the concrete compression height was coming down, stress and strain was increasing.

When bearing capacity did not improve, the local concrete compressive reached ultimate compression strain and crushed, can't continue to bear the pressure resulting in the destruction of the beam.Therefore, in this case the ultimate bearing capacity of the reinforced concrete beam is by compressive strength and ultimate compressive strain of concrete.

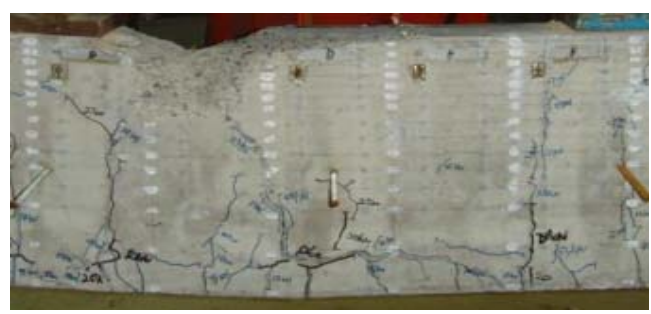

Fig.1 Failure pattern of JD1

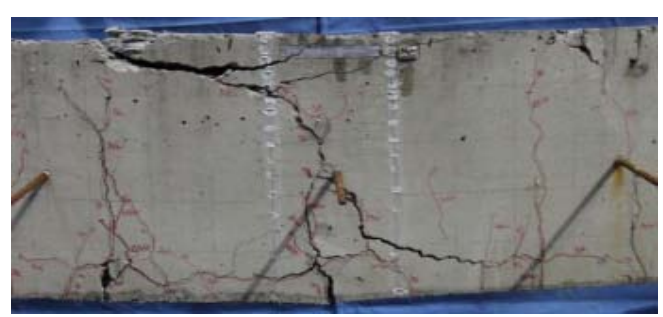

Fig.2 Failure pattern of JD2

\section{JP2 and JP3 Fatigue Mechanism}

When the experimental beam JP2 and JP3 was to destroy, static load test were conducted. Failure pattern of JP2 and JP3 is shown in figure 3 and 4 . When the reinforced concrete beam were destroyed, the concrete compressive had no obvious damage and tensile longitudinal reinforcement fractured in cracks at its widest point.

By the specimen JD1, JD2 and specimen JP2 ,JP3 load-deflection curve comparison (as shown in figure 5), yield bearing capacity and ultimate bearing capacity of specimen JP2 and JP3 are far below specimen JD1 and JD2. When the specimen JP2 and JP3 was to ultimate bearing state, the concrete compressive strain was not big, not give full play to their ability for pressure resistance.But the effective area of tensile longitudinal reinforcement in the wider cracks down to the critical value,caused the fatigue failure of the specimens. While the specimens reached ultimate bearing state after they yield, their bearing capacity had obviously improved. This proved after specimen yield, the tensile stress in the reinforced bear had certain growth and reinforcement achieved ultimate bearing state, led to the final specimens failure.

In a word, the failure modes of specimens JP2 and JP3 are similar to in less reinforcement beam failure mode. In this case the residual ultimate bearing capacity of the reinforced concrete beam is by the residual effective area and residual ultimate strength of reinforcement. 


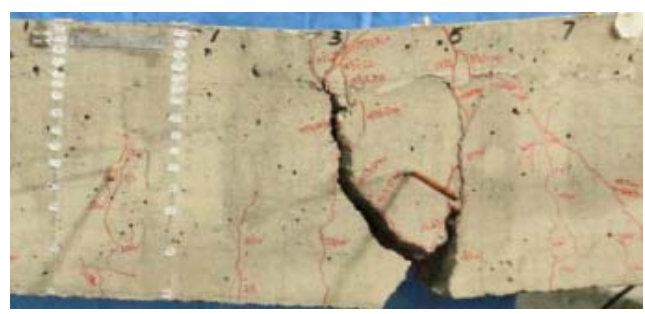

Fig.3Failure pattern of JP2

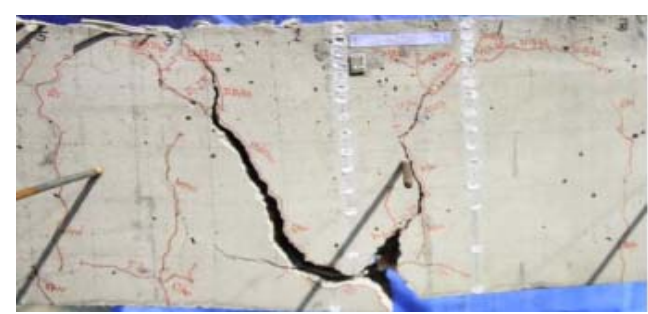

Fig.4Failure pattern of JP3

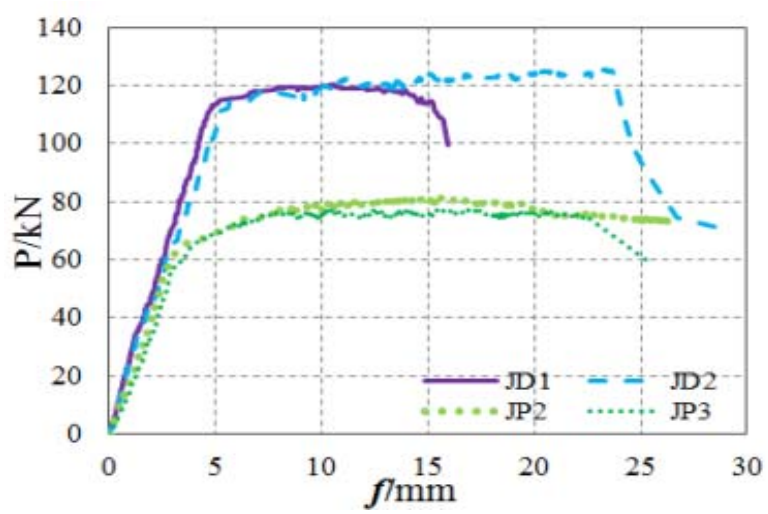

Fig.5The first group and second group of static load deflection curves

\section{JP4 and JP5 Fatigue Mechanism}

The static load test conducted after specimen JP4 and JP5 respectively applied differen cycles far less than their fatigue life.Before static load test, the concrete compressive and tensile longitudinal reinforcement had no obvious fatigue damage phenomenon.Failure pattern of JP4 and JP5 is shown in figure 6 and 7 . When reinforced concrete beams were destroyed, the concrete compressive edge reached the ultimate compression strain and crushed, can't continue to bear the pressure.

The specimen JD1, JD2 and specimen JP4 and JP5 load-deflection curve comparison is shown in figure 8. The ultimate bearing capacity of the specimen JP4 and JP5 had obviously improved. Specimen JP4, JP5 and JD1, JD2 HAD had closed yield point. These showed the effective area of longitudinal reinforcement did not significantly reduce in fatigue load. The bearing capacity and limited deflections of specimen JP4 and JP5 had more obvious growth, because the concrete compressive strength increased due to the repeated compressive stress. This is consistent with the conclusion of literature ${ }^{[9]}$.

In a word, the failure modes of specimens JP2 and JP3 are similar to reinforced beam failure mode.The residual ultimate bearing capacity of the reinforced concrete beam is by the residual effective area and residual ultimate strength of reinforcement.

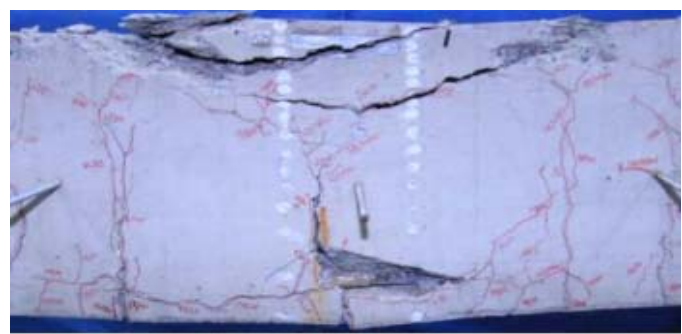

Fig.6 Failure pattern of JP4

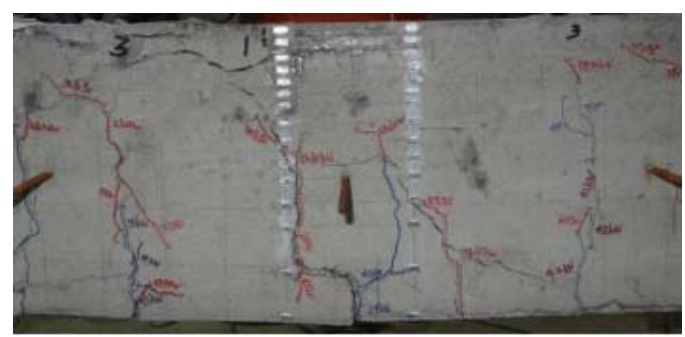

Fig.7 Failure pattern of JP5 


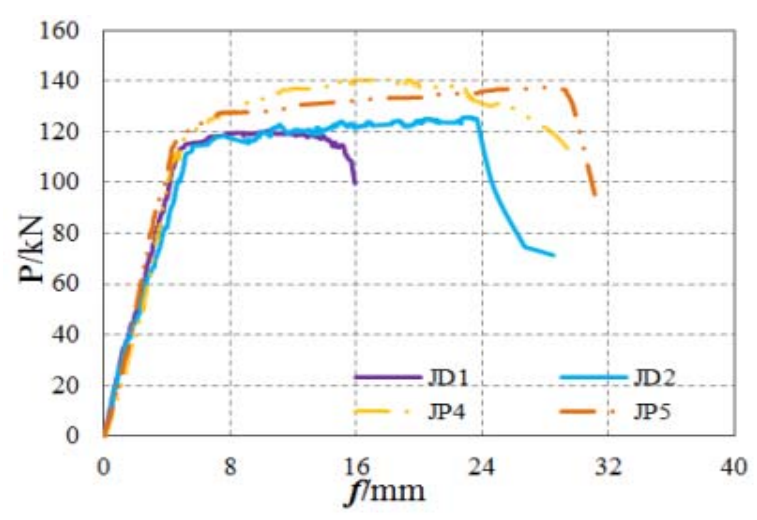

Fig.8 The first group and third group of static load deflection curves

\section{Conclusions}

According to the experimental phenomena, failure mode and the existing relevant theory, reveal the fatigue mechanism of flexural reinforced concrete beams :

Specimen JP2 and JP3 closed to the fatigue failure, the effective area of tensile longitudinal reinforcement decreased, the concrete compressive had no obvious damage and tensile longitudinal reinforcement fractured.The failure modes is similar to in less reinforcement beam failure mode.

Specimen JP4 and JP5 applied differen cycles far less than the fatigue life and had no obvious fatigue damage phenomenon. the concrete compressive ultimate compressive strain and deformability improve due to the lower repeated compressive stress.

\section{Acknowledgements}

This work was financially supported by National Natural Science Foundation of China (51378030), Beijing Natural Science Foundation (8152004), Beijing Municipal Education Commission Research Project (km201410005019) and National Science \& Technology Pillar Program of China (2013BAJ10B03-02).

\section{References}

[1] Moss D S:Axial fatigue of high yield reinforcing bars in air[R]. Transport and Road Research Laboratory, Great Britain, n 622, 1980.

[2] Moss D S: Bending fatigue of high-yield reinforcing bars in concrete[R]. Transport and Road Research Laboratory, Great Britain, 1982.

[3] Zhang B, Phillips D V, Wu K. Effects of loading frequency and stress reversal on fatigue life of plain concrete[J]. Magazine of concrete research, 1996, 48(177): 361-375.

[4] Shibin Li, Cimian Zhu, Hongwei Tang: Building Structure, 2006, 36(2): 51-54(in Chinese)

[5] Ming Zhong, Hailong Wang, Zhongbo Liu: Journal of Building Structures, 2005, 26(2): 94-100(in Chinese)

[6] Ruimin Wang, Guofan Zhao, Qingxiang Wang: China journal of Highway and Transport,Vol.4, No.1, 1991(in Chinese)

[7] Huimin Li,Chuanlin Gu,Buyue Gao. Architectural technology communication. 1982.01.001.

[8] Chunxiao Zhao: Beijing University of Technology.2015(in Chinese)

[9] Awad M E:Strength and deformation characteristics of plain concrete subjected to high repeated and sustained loads[R]. University of Illinois Engineering Experiment Station. College of Engineering. University of Illinois at Urbana-Champaign. 1971. 